\title{
Working Memory Load Influence on Control of Attention among Malaysian Undergraduates
}

\author{
Khairun Emylyana Amin \& Fitri Suraya Mohamad* \\ Dept of Cognitive Sciences, Faculty of Cognitive Sciences and Human Development, \\ Universiti Malaysia Sarawak, 94300 Kota Samarahan, Sarawak, Malaysia
}

\begin{abstract}
The study investigates how working memory affects students' control of attention. A quasi-experimental research is conducted individually on 52 undergraduates of a public university in Malaysia, enrolled in various full-time undergraduate programmes, using Sternberg memory task and Task-switching tests. The reaction time is taken in milliseconds (ms) to differentiate the results for both tasks. The analysis revealed that when memory load was increased, reaction time also escalated. In the task-switching test, when one task was given at any one time, the reaction time was swift; however, when two or more tasks were integrated into one task, the reaction time would subsequently decelerated. Although the study also revealed that there is no significant difference between genders in terms of handling memory load and taskswitching. However, a significant relationship was observed in performances between memory load and task-switching. It is also evidenced in the study that when memory load increases, it compounds the reaction time for task-switching. Results from the study inform course instructors to be aware of cognitive load when chunking information and assigning tasks to students, as their decisions on content quantity bore an effect on what would be remembered when students learn.
\end{abstract}

Keywords: cognitive abilities, memory load, task-switching, Sternberg memory task, working memory

ARTICLE INFO

Email address: mfitri@unimas.my (Fitri Suraya Mohamad)

*Corresponding author

httpt://doi.org/10.33736/jcshd.2454.2021

e-ISSN: 2550-1623

Manuscript received: 29 July 2020; Accepted: 21 December 2020; Date of publication: 25 March 2021

Copyright: This is an open access article distributed under the terms of the CC-BY-NC-SA (Creative Commons Attribution-NonCommercial-ShareAlike 4.0 International License) which permits unrestricted use, distribution, and reproduction in any medium, for non-commercial purposes, provided the original work of the author(s) is properly cited. 


\section{INTRODUCTION}

Memory is where the information is encoded, stored, and retrieved. It is what we remember from the experience that we learn or adapt. Working memory holds the information in our mind. We manipulate the information when we receive feedback. Based on the Baddeley's working memory model, working memory consists of the central executive playing a significant role in switching attention. When a load of working memory increases, it will influence the control of attention toward the item that is held in mind. Working memory handles a small amount of information that can be held in mind and used in the execution of a cognitive task (Cowan, 2014).

In the context of this study, where the target group is made up of university students, the main contention is to understand how these students use their working memory capacity. Many studies have highlighted how active maintenance of task goals is influential to executive function and working memory capacity. Attentional control theory, for instance, suggests that attention selection occurs during early and late processing. Attentional control refers to an individual's ability to pay attention to the provided information and ignored irrelevant information. Conway, Kane, and Engle (2003) stated that cognitive measures of working memory capacity reflect an individual's capacity to hold information in a highly active state despite interference. An individual who can keep information highly active and can retrieve the information show that the individual can control their attention. Cognitive control is necessary to enable flexible allocation of mental resources to perform goal-directed behaviours (Mackie, Van Dam \& Fan (2013). The following questions drive the study; firstly, how do working memory load and task-switching tasks influence the control of attention; second, what is the effect of working memory load on task-switching performance; and finally, is there any difference in working memory performance between genders. Participants are provided two different tasks to measure the control of attention of an individual in receiving the information. The reaction time is recorded in milliseconds (ms).

De Fockert, Rees, Frith and Lavie (2001) found that selective attention can be influenced by working memory load. Hester and Garavan (2005) studied how the load and content of working memory which could affect the control of attention. Kane et al. (2001) described how the ability to control attention is the ability to maintain a stimulus in the presence of a distractor. The information or task goals must be maintained actively to achieve a goal, and as such, it attests to why working memory is important. With the increase of active rehearsal in working memory when dealing with task goals, relevant information would be retained for an extended period. Hester and Garavan (2005) described the condition to hold information in working memory would affect the switching of attention negatively. When there is a lot of information or items received, it will limit an individual's ability to switch from the primary task to secondary task at one time.

Kane et al. (2003) described how cognitive measures of working memory capacity reflect an individual's capacity to hold information in a highly active state despite interference. The same study also explained how cognitive measures of working memory capacity reflect an individual's capacity to hold information in a highly active state despite interference. 
Many studies on cognitive abilities have focused on gender differences. Most found that women performed better than men in memory tasks. Based on Luders et al. (2009) and Gur et al. (2009), they have expected that women would have more advantage when it comes to performing shortterm memory tasks. In their study, they corroborated that there is no difference in working memory tests between gender. Another similar study from Solianik, Brazaitis and Skurvydas (2016) also looked at gender-related differences in attention and memory. Their study revealed that there was no difference in gender, in terms of memory and attention task performances; instead, they observed differences existed in short-term memory and task-switching performances. These findings point to the fact that women and men may have different strengths in cognitive abilities.

Based on the findings from previous literature, this study is designed to find out, in a small scale, how undergraduates at a public university would fare when tested on their short-term memory and task-switching performances. To date, there has not been any recent study that reports a crosssectional investigation on undergraduates who are studying various disciplines, full time, at a Malaysian university. The study is not intended to explore new theories; it is an investigation to determine if a long-held theory about working memory load still holds true in today's scenario, where students are more likely to read and consume information using screen-based formats.

\section{MATERIALS AND METHODS}

The study uses a quasi-experimental approach to investigate the effect of working memory in executive function toward the control of attention among undergraduate students. Quasiexperimental design serves the purpose to investigate the variables selected for the study, as it enables a systematic observation of cognitive reactions on the tasks assigned to the sample group. It was impossible to conduct the experiments at random, as the tasks required intentional focus, effort, and time, on the part of the participants. Quasi-experimental design provides a cost-effective option to collect data, as it does not require elaborate preparations such as those for individual randomised controlled trials or cluster randomised trials.

The participants of the study were made up of 52 undergraduate students from different faculties in a public university in Malaysia. Using a campaign on social media, the participants signed up as they completed an online registration form. Below is a demographic analysis of participants who agreed to be involved in the study (see Table 1). Both genders are represented equally. The majority were aged between 22-23 years old and were in their second and third year of study. Their study year also indicates that most of them have had at least one full year of studying at the university. Although the normality test was not performed in the study, it is clear from the distribution of participants that they represent an almost similar group of characteristics.

Two instruments were deployed in the study. The first one is the Sternberg Memory Task, a computer-based task constructed from a paradigm which focuses on studying the working memory, particularly cognitive processes. The Sternberg Memory task was created to investigate the elimination of unnecessary items from working memory (Oberauer, 2002). The main contention of the task was to list different memory set items of various lengths, which is denoted by the different working memory load. Probe judgment indicates whether the item is part of the memory list presented in the task. 
Table 1: Demographic characteristics of participants

\begin{tabular}{r|lll}
\multicolumn{1}{c}{ Item } & Frequency & Percentage (\%) \\
\hline Gender & Male & & \\
& Female & 25 & $48.1 \%$ \\
& 20 & 27 & $51.9 \%$ \\
& 21 & 6 & $11.5 \%$ \\
& 22 & 8 & $15.4 \%$ \\
& 23 & 20 & $38.5 \%$ \\
Year of Study & 12 & $23.1 \%$ \\
& 24 and above & 6 & $11.5 \%$ \\
& 1st & 8 & $15.4 \%$ \\
& 2nd & 14 & $26.9 \%$ \\
& 3rd & 29 & $55.8 \%$
\end{tabular}

For this study, participants are tested with different working memory loads $(1,2,3,4,5$ and 6 number lists). A list of numbers is shown to the participants and they are required to press the ' $\mathrm{F}$ ' key to indicate that the word shown is part of the assigned memory list, while they would press the ' $\mathrm{J}$ ' key to indicate that the word is not part of the memory list. The next task is to key in the list of numbers in sequence. Reaction time (RT) is recorded as a data to study the differences between the RT of the manipulated working memory load. The task requires 5 to 10 minutes to complete.

The second task is called Task-switching; the instrument is acquired from a website called PsyToolKit.org, developed by Gijsbert Stoet, a professor in the School of Social Sciences at Leeds Beckett, United Kingdom. The computer-based task focuses on observing the ability of participants in task switching. The instrument is remarkably similar to Roger and Monsell's paradigm. The task-switching paradigm is constructed to study about the working memory and attention. Participants are given the first task, in which they need to classify vowels and consonants; the second task requires them to classify odd and even numbers. Consequently, both types of tasks are presented simultaneously, and participants are provided five minutes to complete the task.

A pilot study was conducted on 21 participants to ensure that both instruments are usable for the intended study. The Cronbach's alpha value acquired from the pilot results was analysed for both tasks to measure its reliability. For both paradigms, the Cronbach's alpha value, $\alpha$, were higher than 0.7, proving that both tests were reliable. The Cronbach's Alpha for Sternberg memory task was $\alpha=0.901$, and for Task-switching, the value of $\alpha=0.752$.

In the actual study, 56 participants were recruited, and each was given 10 minutes to attempt the two tasks. As the participants were all enrolled as full-time students, the short timeframe for their involvement in the study was necessary, to ensure that it will not substantially affect their class schedules. The participants were also required to sign a consent form before participating in the 
study to ensure ethical concerns about the study are fully understood and agreed upon, before their participation commenced.

\section{RESULTS}

There are six levels of memory load (Levels 1,2,3,4,5 and 6 respectively) which were conducted on the participants. Reaction time (RT), measured in milliseconds (ms), were taken to record every participant's response rate that indicates their individual control of attention. Participants will be given a list of number between 1 until 6 numbers which need to be remembered. Each number will appear for 500ms. Respondents were instructed to decide either the number appeared is present or absent in the lists. Another task is respondents were asked to type the complete list in the correct order for each trial. There is no time limit for the respondents to respond to the stimuli but if only the response is correct, the time taken will be included in the data. Table 2 presents the analysis of working memory load's influence on the control of attention.

Table 2: Analysis of working memory load influence on the control of attention (in millisecond)

\begin{tabular}{llllll}
\hline & N & Minimum & Maximum & Mean & Std. Deviation \\
\hline Memory Load 1 & 52 & 1056 & 8470 & 2565.40 & 1582.61 \\
Memory Load 2 & 52 & 1161 & 5765 & 2232.35 & 938.44 \\
Memory Load 3 & 52 & 1066 & 35365 & 2959.97 & 4740.39 \\
Memory Load 4 & 52 & 1082 & 7479 & 2615.49 & 1238.56 \\
Memory Load 5 & 52 & 0 & 6663 & 2844.45 & 1300.18 \\
Memory Load 6 & 52 & 1500 & 20985 & 3626.69 & 2990.46 \\
\hline
\end{tabular}

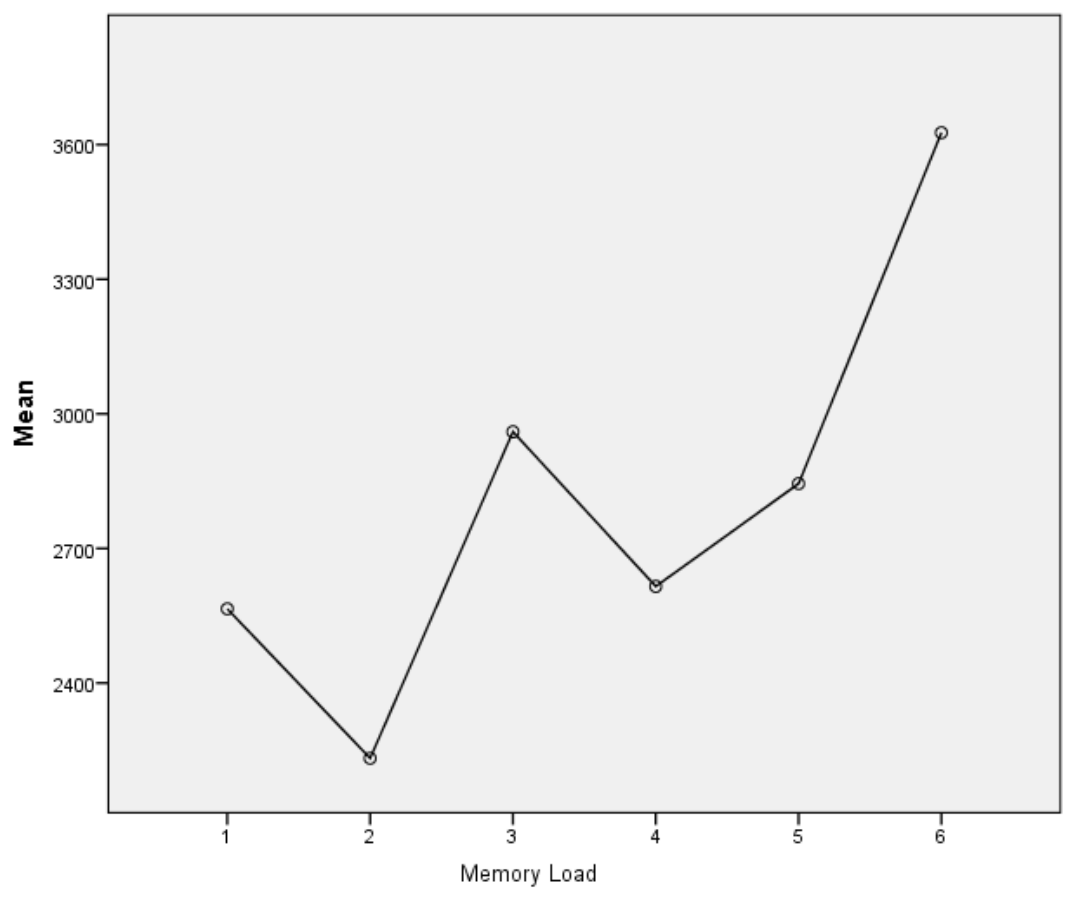

Figure 1. Mean reaction time versus memory load 
When plotted using a graph, the Sternberg Memory task's results are depicted in Figure 1. It shows the precariousness of working memory when participants are provided with increasing degrees of memory load. For the fifth memory task, participants were unable to respond correctly to the given stimuli. Although the response time was recorded for all stimuli, when the stimuli for the given length was not responded correctly, the data recorded would show a score of zero (in the case of the fifth task).

In another task, which investigated task-switching performance, and how it affects the control of attention, participants displayed a constantly increasing amount of reaction times required to process the tasks, using their working memory. There are three levels of task-switching - single task, task repeat, and task-switch. The single task denotes a requirement to conduct one task at a time, and in the case of this study, a letter task was given at one time, followed by a number task. The task repeat task provides letter and number stimuli to be attempted by the participant, and the same items are repeatedly presented after the first attempt. The final task involves task switching, where two tasks (letters and numbers were also used) were integrated as one task, and participants were required to attempt switching from one task to another within a given timeframe. The result of the computer-based task is termed as "task switch cost," which depicts the measurement of performance when participants switch between competing tasks, which in turn illustrates their control process. Table 3 below presents the analysis of task-switching performance on the control of attention, based on the performances observed in the study.

Table 3: Analysis of task-switching performance on the control of attention (in millisecond)

\begin{tabular}{llllll}
\hline & N & Minimum & Maximum & Mean & Std. Deviation \\
\hline Single Task Blocks & 52 & 539 & 2496 & 897.90 & 340.593 \\
Task Repeat Trials & 52 & 584 & 1696 & 1134.63 & 270.251 \\
Task Switch Trials & 52 & 708 & 2397 & 1528.62 & 372.665 \\
\hline
\end{tabular}

Table 3 shows the analysis of task-switching performance which involves the minimum, maximum, mean, and standard deviation values of the reaction time (RT) in milliseconds (ms). Minimum reaction time for task switch trial is $708 \mathrm{~ms}$ while the maximum time is $2397 \mathrm{~ms}$. When plotted in a graph (see Figure 2), the performances gradually increased in value, indicating a greater control of attention. 


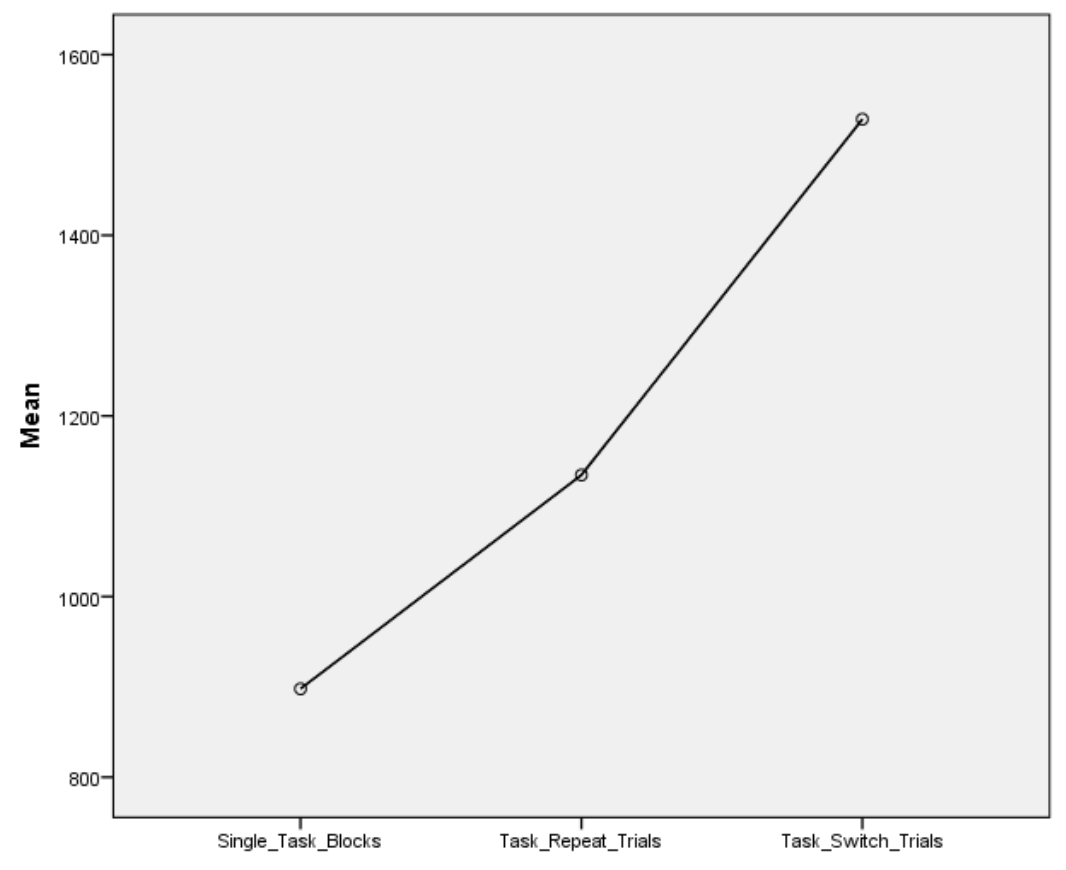

Figure 2. Mean reaction time versus task-switching trials

To investigate gender-based differences in terms of memory load, it showed that females performed in a shorter time compared to the males in the participant group. Table 4 presents the values for mean, standard deviation and standard error mean.

Table 4: Mean comparison between genders for memory load (in millisecond)

\begin{tabular}{llllll}
\hline & Gender & N & Mean & Std. Deviation & Std. Error Mean \\
\hline Memory Load & Male & 25 & 3069.46 & 1930.018 & 386.004 \\
& Female & 27 & 2564.73 & 842.811 & 162.199 \\
\hline
\end{tabular}

Table 5 below presents the values of working memory load between both genders (male $=$ $3069.46 \mathrm{~ms}$, female $=2564.73 \mathrm{~ms}$ ), showing how female participants illustrated a slightly faster response rate compared to their male peers $\left(\mathrm{t}_{32.294}=1.205, \mathrm{p}>0.05\right)$.

Table 5: Independent sample t-test of working memory load between genders (in millisecond)

\begin{tabular}{|c|c|c|c|c|c|c|c|c|c|c|}
\hline & \multicolumn{2}{|c|}{\begin{tabular}{|l|} 
Levene's \\
Test for \\
Equality of \\
Variances
\end{tabular}} & \multicolumn{7}{|c|}{ t-test for Equality of Means } \\
\hline & & \multirow[b]{2}{*}{$\mathbf{F}$} & \multirow[b]{2}{*}{ Sig. } & \multirow[b]{2}{*}{$\mathbf{t}$} & \multirow[b]{2}{*}{ df } & \multirow{2}{*}{$\begin{array}{l}\text { Sig. (2- } \\
\text { tailed) }\end{array}$} & \multirow{2}{*}{$\begin{array}{c}\text { Mean } \\
\text { Difference }\end{array}$} & \multirow{2}{*}{$\begin{array}{l}\text { Std. Error } \\
\text { Difference }\end{array}$} & \multicolumn{2}{|c|}{$\begin{array}{l}\text { 95\% Confidence } \\
\text { Interval of the } \\
\text { Difference }\end{array}$} \\
\hline & & & & & & & & & Lower & Upper \\
\hline \multirow[t]{2}{*}{$\begin{array}{l}\text { Memory } \\
\text { Load }\end{array}$} & $\begin{array}{l}\text { Equal variances } \\
\text { assumed }\end{array}$ & 4.177 & .046 & 1.238 & 50 & .221 & 504.7288 & 407.672 & -314.104 & 1323.561 \\
\hline & $\begin{array}{l}\text { Equal variances } \\
\text { not assumed }\end{array}$ & & & 1.205 & 32.294 & .237 & 504.7288 & 418.697 & -347.824 & 1357.282 \\
\hline
\end{tabular}


When comparing task-switching performance between genders, it was found that females responded faster than males $\left(t_{50}=1.013, p>0.05\right)$. Table 6 and 7 below presents the mean and independent $\mathrm{t}$-test values for both gender groups.

Table 6: Mean values between genders for task-switching (in millisecond)

\begin{tabular}{llllll}
\hline & Gender & N & Mean & Std. Deviation & Std. Error Mean \\
\hline Task Switch Trials & Male & 25 & 1583.00 & 368.107 & 73.621 \\
& Female & 27 & 1478.26 & 376.642 & 72.485 \\
\hline
\end{tabular}

Table 7: Independent sample t-test of task-switching between genders (in millisecond)

\begin{tabular}{|c|c|c|c|c|c|c|c|c|c|c|}
\hline & \multicolumn{2}{|c|}{$\begin{array}{l}\text { Levene's Test } \\
\text { for Equality of } \\
\text { Variances }\end{array}$} & \multicolumn{7}{|c|}{ t-test for Equality of Means } \\
\hline & & \multirow[b]{2}{*}{$\mathbf{F}$} & \multirow[b]{2}{*}{ Sig. } & \multirow[b]{2}{*}{$\mathbf{t}$} & \multirow[b]{2}{*}{ df } & \multirow{2}{*}{$\begin{array}{l}\text { Sig. (2- } \\
\text { tailed) }\end{array}$} & \multirow{2}{*}{$\begin{array}{c}\text { Mean } \\
\text { Difference }\end{array}$} & \multirow{2}{*}{$\begin{array}{l}\text { Std. Error } \\
\text { Difference }\end{array}$} & \multicolumn{2}{|c|}{$\begin{array}{l}95 \% \text { Confidence } \\
\text { Interval of the } \\
\text { Difference }\end{array}$} \\
\hline & & & & & & & & & Lower & Upper \\
\hline \multirow[t]{2}{*}{$\begin{array}{l}\text { Task Switch } \\
\text { Trials }\end{array}$} & $\begin{array}{c}\text { Equal } \\
\text { variances } \\
\text { assumed }\end{array}$ & .042 & .838 & 1.013 & 50 & .316 & 104.741 & 103.409 & -102.962 & 312.443 \\
\hline & $\begin{array}{c}\text { Equal } \\
\text { variances not } \\
\text { assumed }\end{array}$ & & & 1.014 & 49.846 & .316 & 104.741 & 103.316 & -102.791 & 312.273 \\
\hline
\end{tabular}

Despite the better performance shown by female participants in the study, we found that there was no significant relationship between memory load and task-switching. Table 8 presents the mean and standard deviation values, and Table 8 shows the correlation test values acquired from the data collected.

Table 8: Memory load and Task-switching (in millisecond)

\begin{tabular}{llll}
\hline & Mean & Std. Deviation & N \\
\hline Memory Load & 2807.39 & 1476.45 & 52 \\
Task Switch Trials & 1528.62 & 372.67 & 52 \\
\hline
\end{tabular}

Table 9. Correlations between Memory load and Task-switching

\begin{tabular}{cccc}
\hline & & Memory Load & Task_Switch_Trials \\
\hline Memory Load & Pearson Correlation & 1 & .244 \\
& Sig. (2-tailed) & & .081 \\
& $\mathrm{~N}$ & 52 & 52 \\
\hline Task_Switch_Trials & Pearson Correlation & .244 & 1 \\
& Sig. (2-tailed) & .081 & 52 \\
\hline & $\mathrm{N}$ & 52 & \\
\hline
\end{tabular}

Table 9 shows a positive correlation between memory load $(\mathrm{M}=2807.39 \mathrm{SD}=1476.45)$ and taskswitching $(\mathrm{M}=1528.62 \mathrm{SD}=372.67), \mathrm{r}=0.244, \mathrm{p}<0.05, \mathrm{n}=52$. Consequently, it is concluded 
that working memory load and task-switching performance have a statistically significant linear relationship $(\mathrm{p}<0.05)$.

\section{DISCUSSION}

Using the Sternberg Memory Task, when memory load increases, the time that was taken by participants in the study would consequently escalate. The control of attention seemed to be affected by the increase of memory load as well. The findings correlate with Sternberg's own observations (1969), in which he stated that the mean response time would increase in a linear manner with sequence length. Sequence length is referred to as the number of memory load present. The present study corroborates with Sternberg, and it was seen how individual participants were able to respond faster when two tasks are done separately.

One of the contentions of the study was also to investigate differences in performances between genders. However, it was observed that there was no significant difference in working memory load between male and female participants. Memory load task did not appear to have any effect on gender differences. Both male and female performed equally well, albeit the slightest variations of reaction times recorded between them. However, for task-switching, females seemed to perform at a faster rate than males. The finding is in alignment a study by Stoet and colleagues (2013) who also compared the performance of women and men in task-switching paradigm, and they found that women performed better than men in their study.

The present study also found that working memory influenced task-switching performance and that when working memory load increased, the task switching performance inevitably slowed down. Over time, the reaction time for task-switching performance would improve. There is a positive correlation between memory load and task-switching; when memory load increases, taskswitching performance would also be slowing down. The findings are like one reported by Hester and Garavan (2005), which also found that there was a significant difference in memory load and task-switching performances.

\section{CONCLUSION}

The study investigated the effect of working memory in the executive function on the control of attention. It explores the performances of 52 undergraduate students at a public university, to understand how they deal with their control of attention, using the executive function of their working memory. In task-switching, when a task is assigned at a given time, the recorded reaction time is fast; however, when two or more tasks are assigned at a given time, the reaction time decreases. The study also attempted to look at gender differences in dealing with executive function. However, we found that there was no significant difference between genders in terms of memory load and task switching; however, females were recorded to be more able to respond at a faster rate compared to their male peers.

Findings recorded in this small-scale study have strengthened those found by previous research on the same scope of research, in that, when memory load increases, the reaction time which was taken by participants of the study also increases. Even with the advances in technology today, as 
humans increasingly consume screen-based contents, the findings from the study have shown that the amount of content presented at any one time would affect the speed and ability to process information. The ability to cognitively process information is still determined by a person's control of attention, as evidenced four decades ago by Sternberg (1969) and the phenomenon still holds true today in the $21^{\text {st }}$ century. The study noticeably opens an opportunity for course instructors to reflect, review and reassess the chunking of learning contents in their courses. Chunking of information is useful to maintain clarity of learning tasks and optimise the quality of learning experience.

\section{REFERENCES}

Cowan, N. (2014). Working memory underpins cognitive development, learning, and education. Educational Psychology Review, 26(2), 197-223. DOI: 10.1007/s10648-013-9246-y

De Fockert, J. W., Rees, G., Frith, C. D., \& Lavie, N. (2001). The role of working memory in visual selective attention. Science, 291(5509), 1803-1806.

Hester, R., \& Garavan, H. (2005). Working memory and executive function: The influence of content and load on the control of attention. Memory \& cognition, 33(2), 221-233.

Kane, M. J., \& Engle, R. W. (2003). Working-memory capacity and the control of attention: the contributions of goal neglect, response competition, and task set to Stroop interference. Journal of Experimental Psychology: General, 132(1), 47.

Luders, E., Gaser, C., Narr, K. L., \& Toga, A. W. (2009). Why sex matters: brain size independent differences in gray matter distributions between men and women. Journal of Neuroscience, 29(45), 1426514270. DOI: 10.1523/JNEUROSCI.2261-09.2009

Mackie, M. A., Van Dam, N. T., \& Fan, J. (2013). Cognitive control and attentional functions. Brain and cognition, 82(3), 301-12. DOI:10.1016/j.bandc.2013.05.004

Oberauer, K. (2002). Access to information in working memory: exploring the focus of attention. Journal of Experimental Psychology: Learning, Memory, and Cognition, 28(3), 411. DOI: 10.1037/0278-7393

Solianik, R., Brazaitis, M., \& Skurvydas, A. (2016). Sex-related differences in attention and memory. Medicina, 52(6), 372-377. DOI: 10.1016/j.medici.2016.11.007

Sternberg, S. (1969). Memory-scanning: Mental processes revealed by reaction-time experiments. American scientist, 57(4), 421-457.

Stoet, G. (2010). PsyToolkit: A software package for programming psychological experiments using Linux. Behavior Research Methods, 42(4), 1096-1104. DOI: 10.3758/BRM.42.4.1096 